\title{
Exploring the Economic Growth of Minority Autonomous Regions Based on the Solow Model_-Take Enshi Tujia and Miao Autonomous Prefecture in Hubei as an example
}

\author{
Shasha Zhu ${ }^{1, a^{*}}$, Guimei Wu ${ }^{1, b}$, Yuting Ye ${ }^{1, \mathrm{c}}$, Yitong Cai ${ }^{1, \mathrm{~d}}$, and Weili Yang ${ }^{1, \mathrm{e}}$ \\ ${ }^{1}$ South-Central University for Nationalities, School of Economics, Hongshan, Wuhan, China
}

\begin{abstract}
The economic stability and sustainable development of ethnic minority autonomous regions is an important guarantee for promoting China's economic growth and national harmony. Based on the Solow model, the economic growth factors of Enshi Tujia and Miao Autonomous Prefecture in Hubei Province (hereinafter referred to as "Enshi Prefecture of Hubei Province") were measured and analyzed and then extended to the economic development of the entire ethnic regions in China. Through domestic and foreign comparisons, under the premise of correct understanding and analysis of the basic laws and characteristics of economic growth in ethnic areas, this paper gives appropriate economic development suggestions to promote the rapid and stable economic development of ethnic areas in China.
\end{abstract}

\section{Introduction}

Since the reform and opening up, the economy of the ethnic autonomous regions has developed by leaps and made historic progress. As a social, economic, and political region, the national autonomous region's rapid and stable economic growth is the fundamental guarantee for maintaining the national unity, social progress, and common unity of our country. Enshi Tujia and Miao Autonomous Prefecture is the youngest autonomous prefecture in China and the only ethnic minority autonomous prefecture in Hubei Province. With the support of the central government's economic policies, Enshi Prefecture has made great progress, and its economic independence has been continuously strengthened. However, as the total economic volume continues to grow, a series of problems such as resource constraints, environmental damage, and capital deepening have also emerged. The problems of sustained economic growth, coordinated social development, and economic transformation need to be resolved urgently ${ }^{1}$.

Based on the Solow model to analyze the factors of economic growth in ethnic regions, we return to the source of growth, pay attention to the impact of various factors on economic growth, and identify the types of economic growth, which will help us correctly understand the characteristics and trends of economic growth. Through the analysis of the multi-factors of the growth source, correct policy measures are adopted to promote economic growth and transformation, correct the distortion of factor allocation, expand effective supply, increase total factor productivity, and promote the sound and rapid development of ethnic regions.

\section{Calculation method of economic growth factors -- Solow model}

The Solow model, also known as the neoclassical economic growth model, was proposed in 1957 by the famous American economist Solow. Its purpose is to study the different effects of multiple factors on the model, which means the influence of different factors on the law and trend of economic growth has different effects ${ }^{2}$. Considering that economic growth can be divided into quantitative growth and qualitative growth, the increase in the quantity of labor and capital in economic growth is distinguished from technological progress. Capital and quantity are measured separately according to different types. Total factor productivity refers to the total production function and growth equation with constant returns to scale, which means the ratio of output to total factor input. The part where the output growth rate exceeds the factor input growth rate is called the total factor growth rate. This theory attributes the increase in total factor productivity to technological progress, which includes not only the contribution of technological progress in production to economic growth, but also the contribution of organizational management innovation, specialization, knowledge progress, and production innovation ${ }^{3}$. This article also uses the Solow model to measure the TFP growth rate of Enshi Prefecture in Hubei Province from 2015 to 2018. Empirical analysis has a great effect on optimizing the national economic structure, improving total factor productivity, and promoting stable economic growth.

The total production function is

$$
Y_{\mathrm{t}}=A(\mathrm{t}) F\left(\mathrm{x}_{t}\right)
$$

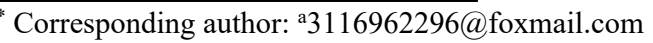

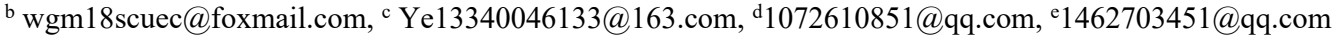


$Y_{\mathrm{t}}$ is the output in year t. $\mathrm{x}_{t}=\left(\mathrm{X}_{1}, X_{2}, X_{3}, \ldots, X_{n}\right)$ represents the factor input vector. $\mathrm{A}(\mathrm{t})$ indicates that the marginal rate of substitution between input elements will not be affected by technological progress. For the convenience of research, we assume that $F(t)$ is a first-order homogeneous function, which means that the return to scale of the inputs of all factors of production remains unchanged. We transform the formula (1), derivate the two sides of $t$ at the same time to obtain the functional formula, and then divide the obtained function by the formula (1) to obtain

$$
\Delta Y_{t} / Y=\Delta A / A+\sum_{\mathrm{i}=1}^{\mathrm{n}} \delta_{i}\left[\Delta X_{\mathrm{i}, t} / X_{\mathrm{i}, \mathrm{t}}\right]
$$

$\delta_{i}$ represents the output share of each input factor.

\subsection{Accounting for TFP growth rate in Enshi Prefecture}

In specific accounting, the C-D production function of the two elements of capital and labor is usually used. Given a competitive market, exogenous technology and constant returns to scale, we use the following production model.

$$
Y_{t}=A K_{t}^{\alpha} L_{t}^{\beta}
$$

$Y_{t} 、 \mathrm{~K}_{\mathrm{t}} 、 \mathrm{~L}_{\mathrm{t}}$ respectively represent the output, capital stock, and labor input of Enshi Prefecture in year t. A represents total factor productivity. The range of $\alpha$ is $0-1$, which represents the production elasticity of capital. $\beta$ represents the production elasticity of labor. $\alpha$ plus $\beta$ equals 1 . According to Solow's argument, A is another factor of economic growth in addition to $\mathrm{K}$ and $\mathrm{L}$. Solow defines the residual value $\mathrm{A}$ as TFP, which means that the improvement of total factor productivity is used to reflect technological progress ${ }^{4}$. That is to say, under the condition of constant labor and capital, the increase in output is due to the change of technology, that is, the effect of variable A can be expressed by the following formula.

$$
\operatorname{TFP}_{t}=Y_{t} / K_{\mathrm{t}}^{\alpha} \cdot L_{t}^{\beta}
$$

According to the Solow residual method, the growth rate of total factor productivity (TFP) can be obtained, and formula (1) can be deformed to obtain

$$
\triangle A / A=\triangle Y / Y-\alpha \cdot \triangle K / K-\beta \bullet \triangle L / L
$$

$\triangle \mathrm{A} / \mathrm{A}$ is the growth rate of TFP. Taking the natural logarithm of the C-D production function (3), we can get

$$
\ln Y_{t}=\ln A+\alpha \ln K_{t}+\beta \ln L_{t}+\varepsilon_{t}
$$

Capital stock can be estimated in different ways. This article adopts the perpetual inventory method pioneered by Goldsmith, and the available capital stock is as follows

$$
K_{t}=I_{t} / P_{t}+\left(1-\delta_{t}\right) K_{t-1}
$$

$\mathrm{K}_{0}$ represents the base period capital stock.

$$
K_{0}=I_{0} /(g+\delta)
$$

$I_{0}$ is base period investment. $\mathrm{g}$ is average annual growth rate of investment. $\delta$ is average annual asset depreciation rate. Through the analysis of the data of Enshi Prefecture from 2005 to 2018 , it is concluded that the capital stock of the base period in 2005 was 81.594 billion yuan and the base period investment was 21.521 billion yuan. The average annual growth rate of investment from 2005 to 2018 was $0.19939 . \delta$ is 0.064367 directly calculated.

In order to reduce the measurement error of factors such as price changes, this article chooses to use real GDP for calculation. By sorting out the "Statistical Yearbook of Enshi Tujia and Miao Autonomous Prefecture in Hubei Province" from 2005 to 2018 and using SPSS software to perform regression analysis on formula (6), and calculating the coefficients $\alpha$ and $\beta$, the data shown in Table 1 can be obtained.

Table.1. Economic growth composition data of Enshi Tujia and Miao Autonomous Prefecture from 2005 to 2018

\begin{tabular}{lllllll}
\hline Year & $\begin{array}{l}\text { Real GDP } \\
(\mathbf{1 0 0} \\
\text { million } \\
\text { yuan) }\end{array}$ & $\begin{array}{l}\text { Capital } \\
\text { deposit } \\
\text { million } \\
\text { yuan) }\end{array}$ & $\begin{array}{l}\text { Labor } \\
\text { input (ten } \\
\text { thousand) }\end{array}$ & $\begin{array}{l}\text { TFP } \\
\text { growth } \\
\text { rate } \\
(\%)\end{array}$ & $\begin{array}{l}\text { capital- } \\
\text { output } \\
\text { ratio } \\
(\mathbf{K} / \mathbf{Y})\end{array}$ & $\begin{array}{l}\text { K/Y } \\
\text { growth } \\
\text { rate } \\
(\%)\end{array}$ \\
\hline $\mathbf{2 0 0 5}$ & 180.65 & 815.94 & 12.84 & 0.0099 & 4.5167 & 0.0353 \\
$\mathbf{2 0 0 6}$ & 196.58 & 937.51 & 14.45 & 0.00889 & 4.7691 & 0.0559 \\
$\mathbf{2 0 0 7}$ & 208.93 & 1042.41 & 19.99 & 0.03028 & 4.9893 & 0.0462 \\
$\mathbf{2 0 0 8}$ & 233.06 & 1255.84 & 20.82 & 0.021 & 5.3885 & 0.08 \\
$\mathbf{2 0 0 9}$ & 263.01 & 1507.28 & 21.39 & -0.01743 & 5.7309 & 0.0635 \\
$\mathbf{2 0 1 0}$ & 299.32 & 1856.35 & 21.44 & -0.03451 & 6.2019 & 0.0822 \\
$\mathbf{2 0 1 1}$ & 355.41 & 2357.47 & 22.37 & 0.00131 & 6.6331 & 0.0695 \\
$\mathbf{2 0 1 2}$ & 379.71 & 2672.47 & 24.03 & 0.01312 & 7.0382 & 0.0611 \\
$\mathbf{2 0 1 3}$ & 417.46 & 3305.11 & 26.59 & -0.01034 & 7.9172 & 0.1249 \\
$\mathbf{2 0 1 4}$ & 456.92 & 4023.04 & 28.25 & 0.04891 & 8.8047 & 0.1121 \\
$\mathbf{2 0 1 5}$ & 498.45 & 4963.12 & 29.76 & 0.00109 & 9.9571 & 0.1309 \\
$\mathbf{2 0 1 6}$ & 538.47 & 5981.97 & 31.41 & 0.04368 & 11.1092 & 0.1157 \\
$\mathbf{2 0 1 7}$ & 571.86 & 7170.67 & 32.28 & 0.04375 & 12.5392 & 0.1287 \\
$\mathbf{2 0 1 8}$ & 607.08 & 8601.05 & 32.86 & 0.0649 & 14.1679 & 0.1299 \\
\hline
\end{tabular}

Data source: 2005-2018 "Statistical Yearbook of Enshi Tujia and Miao Autonomous Prefecture of Hubei Province"

\subsection{Analysis of TFP growth rate in Enshi Prefecture}

It can be seen from Table 1 that since the beginning of the 21st century, the market economy has developed rapidly, and the economy of Enshi Prefecture has developed slowly. Although the GDP growth rate has increased in recent years, the TFP growth rate in Enshi Prefecture has been increasing slowly before 2013. However, the capital-output ratio has increased by about $9 \%$ since 2005 . Figure 1 shows the relative changes in the growth rate of capital-output ratio and the growth rate of TFP. As can be seen from Figure 1, the two showed opposite trends. The TFP growth rate showed a downward trend before 2012. This may be due to the fact that the market economy in Enshi has not yet found a better development direction. The $\mathrm{K} / \mathrm{Y}$ growth rate has increased significantly. From 2012 to 2015 , the TFP growth rate has shown an upward trend as a whole, and the K/Y growth rate has shown a downward trend. In 2016-2018, the two are also opposite trends. 


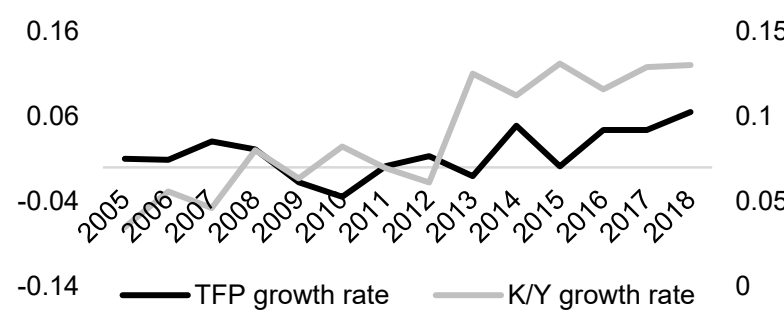

Figure.1. Enshi Tujia and Miao Autonomous Prefecture TFP growth rate and capital output ratio growth rate (2005-2018)

\section{Estimation and testing of the model}

\subsection{Stationarity test}

It can be seen from Table 1 that the actual GDP of Enshi Prefecture from 2005 to 2018 has roughly shown a growth trend. In order to avoid "false regression", this paper conducts unit root tests on each time series data. We define the linear regression model $\ln Y=c+\ln K+\varepsilon$. Then we select the $\mathrm{ADF}$ test and the second-order in the lag difference item through Eviews and get as shown in Figure 2.

\begin{tabular}{lccc}
\hline \hline & & t-Statistic & Prob. $^{*}$ \\
\hline \hline Augmented Dickey-Fuller test statistic & -1.278065 & 0.6058 \\
\hline Test critical values: & 1\% level & -4.057910 & \\
& $5 \%$ level & -3.119910 & \\
& $10 \%$ level & -2.701103 & \\
\hline \hline & & & \\
\hline \hline & & t-Statistic & Prob. $^{*}$ \\
\hline \hline Augmented Dickey-Fuller test statistic & -2.330878 & \multirow{2}{*}{0.8058} \\
\hline Test critical values: & 1\% level & -3.986623 & \\
& 5\% level & -3.086793 & \\
& $10 \%$ level & -2.686623 & \\
\hline \hline
\end{tabular}

Figure.2. Unit root test

It can be seen from the test results that at the level, the $\mathrm{ADF}$ value of the $\ln \mathrm{Y}$ sequence is -1.278065 . The $\mathrm{ADF}$ value of the $\operatorname{lnK}$ sequence is -2.330878 . The ADF values of the two series are both greater than the critical values at $1 \%, 5 \%$ and $10 \%$ significance respectively. So $\ln \mathrm{Y}$ and $\ln \mathrm{K}$ are judged to be non-stationary series. Therefore, it is necessary to carry out a difference test on the two groups of numbers. After the second difference time series test, $\ln \mathrm{Y}$ is stable under $10 \%$ significance, and $\operatorname{lnK}$ is stable under $1 \%, 5 \%$ and $10 \%$ significance. So, it should be significant when the performance is $10 \%$. Both $\ln \mathrm{Y}$ and $\ln \mathrm{K}$ are second-order single integers.

\subsection{Heteroscedasticity test}

In the construction of the auxiliary function in the White test, considering that the model is a one-variable function, the cross products term of the variables is not set. The auxiliary function is $\sigma_{t}^{2} \beta_{0}+\beta_{1} \mathrm{x}_{t}^{2}+\varepsilon_{t}$. Finally, we do the White test in Eviews, as shown in Figure 3.
Heteroskedasticity Test: White

\begin{tabular}{llll}
\hline F-statistic & 0.741088 & Prob. F(5,8) & 0.6140 \\
Obs*R-squared & 4.431801 & Prob. Chi-Square(5) & 0.4891 \\
Scaled explained SS & 1.512489 & Prob. Chi-Square(5) & 0.9116 \\
\hline
\end{tabular}

Figure.3. White Test

$\mathrm{nR}^{2}$ is 0.0741088 . At the $5 \%$ level of significance, the critical value is $\chi_{0.05}^{2}(2)=5.9915$. Because of $n R^{2}<\chi_{0.05}^{2}(2)$, according to the test results, it is judged that there is no heteroscedasticity in the model. So the estimated regression model is

$$
\begin{aligned}
& \ln Y_{t}=1.5320+0.5499 \ln K_{t} \\
& t=(10.79904)(18.47890) \\
& R^{2}=0.9912 \\
& D W=2.1103
\end{aligned}
$$

The regression equation shows that the average elasticity of $\ln Y_{t}$ to $\operatorname{lnK}_{t}$ is 0.5499 . ADF test was performed on the residuals, and the result is showed. At a significance level of $10 \%$, the t-test statistic value was -1.583515 , which was less than the corresponding critical value. This shows that the residual sequence does not have a unit root and is a stationary sequence. From this, it is judged that there is a co-integration relationship between $\ln \mathrm{Y}_{\mathrm{t}}$ and $\ln \mathrm{K}_{\mathrm{t}}$. There is a long-term equilibrium relationship.

\section{Dynamic study of the model}

Finally, according to OLS regression estimation, the coefficients of the model are obtained $\alpha=0.5499$ and $\beta=0.4501$. At the same time, according to $\ln A=\ln \mathrm{y}-\alpha \ln k$, the value of TFP in different years is obtained. In order to facilitate the calculation, this paper selects the average value of A value of 1.02.

$$
Y=A K^{\alpha} L^{\beta}=1.02 K^{0.5499} L^{0.4501}
$$

So, the classical Solow model of economic growth is

$$
\begin{aligned}
& \Delta k=s f(k)-(n+\delta) k \\
& \Delta k=1.02 s k^{0.5499}-(n+\delta) k
\end{aligned}
$$

$\mathrm{s}$ is saving rate. $\mathrm{n}$ is labor population growth rate. $\delta$ is depreciation rate.

In order to achieve a stable state of economic growth in the model, the per capita capital stock is 0 . That is $\Delta \mathrm{k}=0$. Now we must first determine the values of the coefficients in equation (10). S mainly refers to the ratio of per capita savings to disposable income. As the savings statistics of prefecturelevel cities are difficult to obtain, the national average savings rate is about $30 \%$ instead. $n$ is the average annual growth rate of employed persons is adopted, which is about $1.8 \%$. The depreciation rate is approximately $6.4 \%$ when the capital stock is used to calculate the depreciation rate.

$$
\Delta k=1.02 \times 0.3 k^{\mathrm{s} s \mathrm{~s} \%}-(1.8 \%+6.4 \%) k=0.306 k^{\mathrm{ossm}}-0.082 k
$$

This shows that the contribution rates of capital and labor are $54.99 \%$ and $45.01 \%$ respectively in the process of economic development in Enshi Prefecture. It can be judged that the economic development of Enshi Prefecture is mainly driven by investment, which is consistent with the national 
situation. In the case of Enshi Prefecture, total factor productivity increased from 0.0099 in 2005 to 0.0649 in 2018 . Although there have been fluctuations during this period, the overall technological progress rate is still on the rise. When the growth of per capita capital stock is 0 , the corresponding steady-state per capita capital stock $\mathrm{k}^{*}$ and steady-state per capita effective output $\mathrm{y}^{*}$ can be obtained.

When the per capita consumption level is the highest, the golden rule level of the per capita capital stock can be found. At this time, the growth rate of per capita output is equal to the growth rate of depreciation and labor. When $\Delta y / y=n+\delta=8.2 \%, \quad c=f(k)-0.082 k \quad$ reached the maximum value. Through calculation, it is found that the per capita capital stock at this time is lower than the steady state. Therefore, only by appropriately increasing the savings rate and the rate of technological progress can the golden rule level be close to the steady state of the Solow model.

\section{Conclusion and policy implications}

Based on the Solow growth model, this paper conducts a theoretical analysis of the relationship between capital input, labor input and economic growth and an empirical analysis of the economic growth data of Enshi Prefecture from 2005 to 2018. It is found that the amount of investment in science and technology in Enshi Prefecture is relatively weak. At the same time, it has a strong dependence on capital. Enshi Prefecture is a typical ethnic area, affected by various factors in terms of economic development. In order to achieve steady economic growth, we give the following suggestions:

\subsection{Realize government-enterprise investment}

Continuing to play the decisive role of investment is the foundation for the future economic growth of Enshi Prefecture. In terms of needs, the relevant infrastructure conditions of the economy and society lag far behind the provincial capitals. A number of major infrastructure projects need to be built in the fields of transportation, water conservancy, science and technology, ecology, and municipal administration $^{5}$. The government should realize the combination of government and enterprise investment, stick to seek improvement in stability, and take promoting highquality development as the theme to make overall development.

\subsection{Adjust and innovate government regulation and control methods}

The government's regulation and control methods should keep pace with the times, learn from the experience and lessons of various regions, avoid structural distortions caused by excessive investment, and improve investment efficiency. At the same time, we will give full play to the strengths of ethnic regions, scientifically regulate investment, select professional teams for management, and enhance the marketization level of fund management operations.

\subsection{Pay attention to improving total factor productivity}

The low technological growth rate is the main reason for Enshi Prefecture's long-term economic downturn, so improving the technological growth rate is an urgent problem for Enshi Prefecture to solve at present.To increase the technological growth rate, one is to improve the technology to achieve production efficiency. Second, we shall improve the allocation efficiency of resources. Third, we will deepen supply-side structural reform with the new normal in economic development as our overall goal. At the same time, we should pay attention to the investment in education, improve the development of practical science and technology, and inject long-term impetus into the economic growth of Enshi prefecture

\section{References}

1. H. Tian, Analysis of economic growth factors in Minority Areas -- a case study of Tujia and Miao Autonomous Prefecture in Western Hunan, Today's fortune, 04: 41-42 (2021).

2. $\mathrm{P} . \mathrm{Yu}$, Research on China's economic growth trend under the new normal based on Solow model, Qingdao University (2018).

3. C. Qin, Analysis on contribution rate of China's provincial economic factors based on Solow economic growth model, Statistics and management, 06: 60-61 (2017).

4. M. Zhao, J. Zhao, measurement of the effect of urban innovation on economic growth from the perspective of Solow model: a case study of 35 large and medium-sized cities in China, Research on science and technology management, 22: 78-83 (2019).

5. Z. Zhang, Research on economic growth of Hunan Province Based on Solow model, Times finance, 20: 8586 (2017). 